\title{
AVALIAÇÃO DAS CONCENTRAÇÕES DE NITRATO NAS ÁGUAS MINERAIS PRODUZIDAS NA REGIÃO DA GRANDE NATAL
}

\author{
Mariana Magna Santos da Nóbrega \\ Tecnóloga em Controle Ambiental - CEFETRN \\ E-mail: marianamagna@yahoo.com.br
}

André Luis Calado Araújo

Professor do CEFETRN, Pesquisador do CNPq - Nível 2. E-mail: acalado@ cefetrn.br

Jerônimo Pereira dos Santos

Professor do CEFETRN. E-mail: jeronimo@cefetrn.br

\section{RESUMO}

A Região Metropolitana de Natal, no estado do Rio Grande do Norte, é detentora de grandes reservas de águas subterrâneas pertencentes ao aqüífero Dunas/Barreiras. Essas águas são utilizadas pela população para seu abastecimento e consumo industrial. Além disso, essas reservas possuem características de águas minerais, localizando-se principalmente nos municípios de Parnamirim e Macaíba na região sul e no município de Extremoz, na parte norte. Em contrapartida, o crescimento urbano acelerado da Grande Natal, associado com a falta de esgotamento sanitário e drenagem adequada, resultaram no aporte de carga contaminante originária, principalmente, de fossas e sumidouros domésticos em direção às águas do aquífero. Este artigo tem como finalidade avaliar as concentrações de nitrato nas fontes de águas minerais, tomando-se como base a proximidade de poços contaminados por esses teores. Para isso, basicamente, se comparou dados que representavam concentrações de $\mathrm{NO}_{3}{ }^{-}$em águas minerais, com teores de nitrato pertencentes à poços de abastecimento público ou particulares da região circunvizinha a essas águas, ambos obtidos através dos projetos de Iniciação Científica desenvolvidos no CEFET-RN. As atividades que fizeram parte da realização do trabalho foram constituídas pela localização da área de estudo, seleção dos poços a serem analisados, análises laboratoriais do íon nitrato, tabulação e tratamento dos dados obtidos, além das considerações a respeito da qualidade das águas subterrâneas. Através dos resultados obtidos foi possível demonstrar a que níveis de concentração de nitrato estão os poços produtores de água mineral, destacando-se dois, dos dez selecionados, que apresentaram valores acima de $10 \mathrm{mg} / \mathrm{L}$.

PALAVRAS-CHAVE: água mineral, águas subterrâneas, aqüífero Dunas/Barreiras, contaminação, nitrato e Região Metropolitana de Natal.

\section{EVALUATION OF NITRATE CONCENTRATIONS ON MINERAL WATERS PRODUCED IN THE METROPOLITAN REGION OF NATAL}

\begin{abstract}
The Metropolitan Region of Natal, located in the state of the Rio Grande do Norte, is detainer of great reserves of groundwater from Dunas/Barreiras aquifer. These waters are used by the population for your supplying and industrial consumption; moreover these reserves possess mineral water characteristics, situated mainly in the cities of Parnamirim
\end{abstract}


and Macaíba, in the south region, and in the city of Extremoz, in the part north. However, the fast urban growth of Natal, associate with the lack of sanitation and drainage, has caused the increase of contamination, mainly by the infiltration of septic tanks effluents in soil. The presented work has as main purpose the evaluation of nitrate concentrations in the mineral water sources, taking in consideration the proximity of wells already contaminated by nitrate. For this, data of nitrate concentrations in mineral waters were compared with those from wells of the public or private supplying from the surrounding region. The work comprised the localization of the study area, selection wells to collect samples, laboratory analyses of the ion nitrate, treatment of data, and the global evaluation of underground waters quality. Through the results was possible to demonstrate the levels of nitrate concentration on mineral water wells, including two with concentration higher than 10 $\mathrm{mg} / \mathrm{L}$.

KEY WORDS: mineral water, underground waters, aquifer Dunas/Barreiras, contamination, nitrate and Metropolitan Region of Natal. 


\section{AVALIAÇÃO DAS CONCENTRAÇÕES DE NITRATO NAS ÁGUAS MINERAIS PRODUZIDAS NA REGIÃO DA GRANDE NATAL}

\section{INTRODUÇÃO}

A utilização das águas subterrâneas na cidade de Natal data do século passado, através do uso de cacimbões. No ano de 1902 foram construídos os primeiros poços tubulares. Em 1924, foi desenvolvido o primeiro projeto para abastecimento d'água da cidade, que previa a perfuração de poços tubulares, sendo esse, com o passar dos anos, modificado e ampliado para que, disto feito, o consumo satisfatório fosse garantido. (Melo e Queiros, 1998).

Seguindo essa mesma tendência os municípios vizinhos à cidade do Natal também passaram a explorar as águas subterrâneas como o principal manancial hídrico da região, destacando-se aí os municípios de Parnamirim, Macaíba e Extremoz.

A grande disponibilidade das águas subterrâneas da área que compreende a região Metropolitana de Natal é devido ao aquífero Dunas/Barreiras, o qual é favorecido por condições geológicas que acabam por permitir a infiltração e, consequientemente, renovação dessas águas. Tais águas são utilizadas pela população para seu abastecimento e consumo industrial. Parte dessas reservas subterrâneas também possui características de águas minerais.

Atualmente, o que se observa é que com o crescimento urbano acelerado da Grande Natal, associado com a falta de esgotamento sanitário e drenagem adequada, resultou-se o aporte de carga contaminante originária, principalmente, de fossas e sumidouros domésticos em direção às águas do aqüífero, podendo comprometer também as fontes de água mineral.

Tendo em vista a problemática que envolve o assunto abordado é que se justifica o fato de se aprofundar em discussões e buscar soluções que garantam a qualidade e a segurança das águas subterrâneas.

Neste contexto, o trabalho tem como objetivo avaliar uma possível contaminação, dos poços de águas minerais pelo íon nitrato, tomando-se como parâmetro de referência poços de abastecimento ou particulares localizados nas proximidades dessas fontes e que apresentaram elevadas concentrações de nitrato.

\section{CONTEXTO ATUAL DA REGIÃO METROPOLITANA DE NATAL}

Com o crescimento urbano, os municípios brasileiros passaram a enfrentar o grande desafio de atender, com maior rapidez e eficiência, as crescentes demandas da população por bens e serviços públicos. Diante dessa nova realidade, tornou-se cada vez mais necessário o estabelecimento de soluções conjuntas e integradas entre os diversos municípios.

Seguindo essa tendência nacional, a Região Metropolitana de Natal é estabelecida, inicialmente em 1997, e em 2002 passa a ser integrada por oito municípios: Ceará - Mirim, Extremoz, Macaíba, Natal, Nísia Floresta, Parnamirim, São Gonçalo do Amarante e São José do Mipibu. Posteriormente, em 2005, foi adicionada a cidade de Monte Alegre, totalizando, assim, nove municípios. 
A área correspondente à região da Grande Natal, segundo a Secretaria Municipal de Meio Ambiente e Urbanismo (Prefeitura Municipal do Natal, 2006) abrange uma superfície de 2.722,80 quilômetros quadrados, o que corresponde a 5,16\% do território estadual. Sua população, segundo o Censo Demográfico de 2000, atingiu 1.116.147 habitantes. Isto já representa 40,19\% da população do Rio Grande do Norte concentrada em um restrito espaço do Estado.

Quanto à sua expansão, a Região Metropolitana de Natal cresceu de 1991 a 2000, 2,62\% ao ano. Natal, sua sede, registrou nesse período uma taxa de crescimento anual de $1,80 \%$. Seu entorno, entretanto, apresentou taxas mais elevadas. Destacaram-se, nesse sentido, os municípios de Parnamirim (7,90\%) e São Gonçalo do Amarante (4,90\%). Todos os demais integrantes superaram o percentual de crescimento da capital do Estado: Nísia Floresta (3,60\%), Extremoz (3,10\%), Macaíba (2,70\%), São José de Mipibu (2,40\%), Ceará Mirim $(2,00 \%)$ e Monte Alegre (1,94\%). (Prefeitura Municipal do Natal, op. cit.).

Tendo em vista as taxas de crescimento anual, a região que compreende as cidades de Parnamirim, Macaíba, Extremoz e São Gonçalo do Amarante, se destaca em função das atividades econômicas aí desenvolvidas, dessa forma, observou-se nas últimas décadas o avanço, sem um planejamento adequado e com expansão ocupacional/habitacional principalmente em direção a Parnamirim.

Além disso, essa região, notadamente os municípios de Parnamirim, Macaíba e Extremoz se destacam por possuir um grande número de reservas de águas minerais. 13, das 15 fontes de água mineral do estado se concentram nesses municípios.

\section{LOCALIZAÇÃO DA ÁREA DE ESTUDO}

A região estudada está localizada ao norte e ao sul da cidade de Natal-RN, abrangendo, principalmente, os municípios de Parnamirim, Macaíba e Extremoz. A Figura 1 ilustra a localização dessa área.

\section{CONTAMINAÇÃO POR NITRATO NO AQÜÍFERO DUNAS/BARREIRAS NA REGIÃO METROPOLITANA DE NATAL}

Os sedimentos do Grupo Barreiras são definidos como aqüífero Dunas-Barreiras, caracterizando as formações dunares que, devido a sua elevada porosidade e baixo índice de escoamento superficial, atuam como receptoras das precipitações pluviométricas, constituindo-se em um 'canal' de comunicação com o aqüífero e conseqüentemente, fonte de recarga do Barreiras.

Nesse sentido, a vulnerabilidade do sistema aqüífero ao processo de contaminação das águas é atribuída às feições geomorfológicas e estrutura hidrogeológicas. Essas, por sua vez se caracterizam pela existência do capeamento de areias de dunas, pela formação de bacias fechadas, pela ocorrência de lagoas e, sobretudo pela conexão hidráulica das dunas com os sedimentos Barreiras. (Melo e Queiros, 1998). 


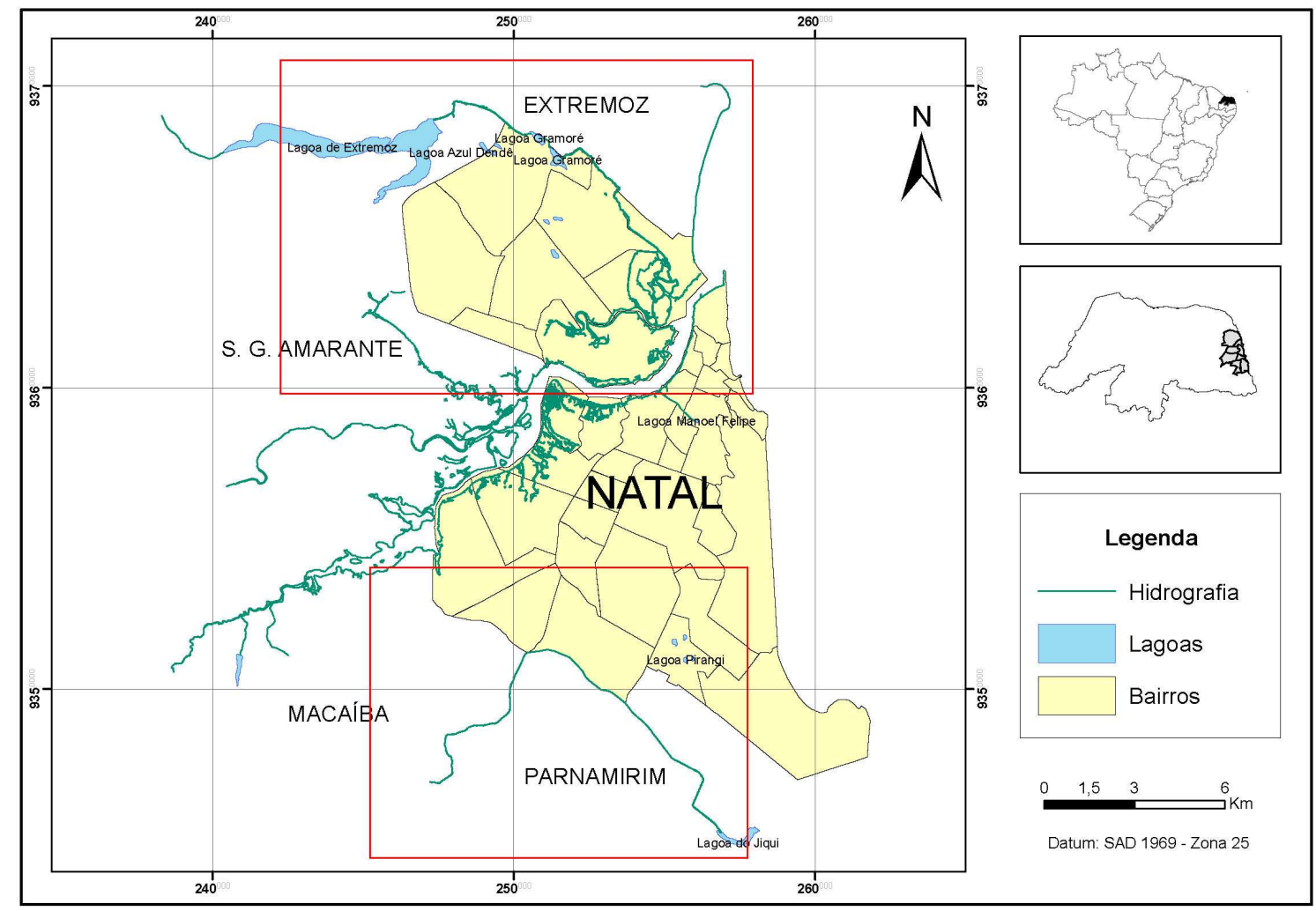

Figura 1: Localização aproximada da área de estudo destacada nos retângulos vermelhos.

Assim, as águas subterrâneas da Região da Grande Natal, que pertencem ao aquífero Dunas/Barreiras, tornaram-se ameaçadas de contaminação devido a sua vulnerabilidade ao processo de degradação pelas atividades do desenvolvimento urbano, destacando-se o sistema de saneamento com disposição local de efluentes domésticos (fossas e sumidouros) e a ocupação irregular e desordenada do terreno.

Em relação à primeira situação, a qualidade da água acaba ficando comprometida, tendo em vista a existência do risco de contaminação das mesmas por nitrato, originados a partir da biodegradação dos excrementos humanos. E do ponto de vista quantitativo, as águas subterrâneas estão sendo afetadas pelas edificações e pavimentações, que reduzem a recarga do sistema e ainda influenciam de forma indireta no aspecto qualitativo, já que o volume d'água para a diluição de contaminantes será menor.

\section{INDÚSTRIAS DE ÁGUA MINERAL NA REGIÃO METROPOLITANA DE NATAL}

O desenvolvimento industrial, seguindo uma tendência natural pelo modelo de civilização adotado, proporcionou a derrocada do tradicional enfoque que caracterizava a água mineral pelo aspecto medicinal, sob o impacto da sua comercialização em larga escala. Somando a isso, os grandes centros urbanos juntamente com a poluição crescente dos mananciais trouxeram consigo a necessidade do tratamento da água para consumo humano e, em contrapartida, um mercado em constante expansão de água mineral usada como bebida ou complemento alimentar 
No Rio Grande do Norte existem 15 marcas de água mineral disponíveis no mercado, sendo que duas dessas pertencem a uma mesma empresa, totalizando assim em $14 \mathrm{o}$ número das indústrias autorizadas a envasar o produto.

De acordo com a tendência mundial, no estado do Rio Grande do Norte, essas águas apresentaram-se em constante expansão até meados de 2005. No entanto, atualmente os engarrafadores desse produto estão preocupados com a quantidade e a qualidade de marcas disponibilizadas para o consumidor. Os empresários acreditam que o mercado local está saturado.

Com o objetivo de buscar informações a respeito das concentrações de nitrato presentes nas águas minerais, a área de abrangência deste trabalho está contida em parte da Região Metropolitana de Natal (Figuras 2 e 3). Os municípios de Extremoz ao norte de Natal, juntamente com Parnamirim e Macaíba ao sul de Natal, destacam-se por possuírem a maioria das fontes minerais exploradas no estado do Rio Grande do Norte. No entanto, tendo em vista uma comparação-comprovação dos dados, alguns bairros, que fazem fronteira com os municípios citados, da cidade de Natal foram selecionados para também fazerem parte da região ora estudada.

A metodologia de trabalho, basicamente, foi a reunião e a tabulação dos resultados adquiridos através do levantamento dos dados obtidos em coletas de campo e das análises químicas do íon nitrato realizadas junto ao laboratório de pesquisa do CEFETRN (dados de 2005 e 2006), juntamente com levantamentos compilados na bibliografia consultada que possibilitou o fornecimento e seleção de mais 41 poços de água subterrânea com suas respectivas concentrações de nitrato (dados de 2002 e 2004). 


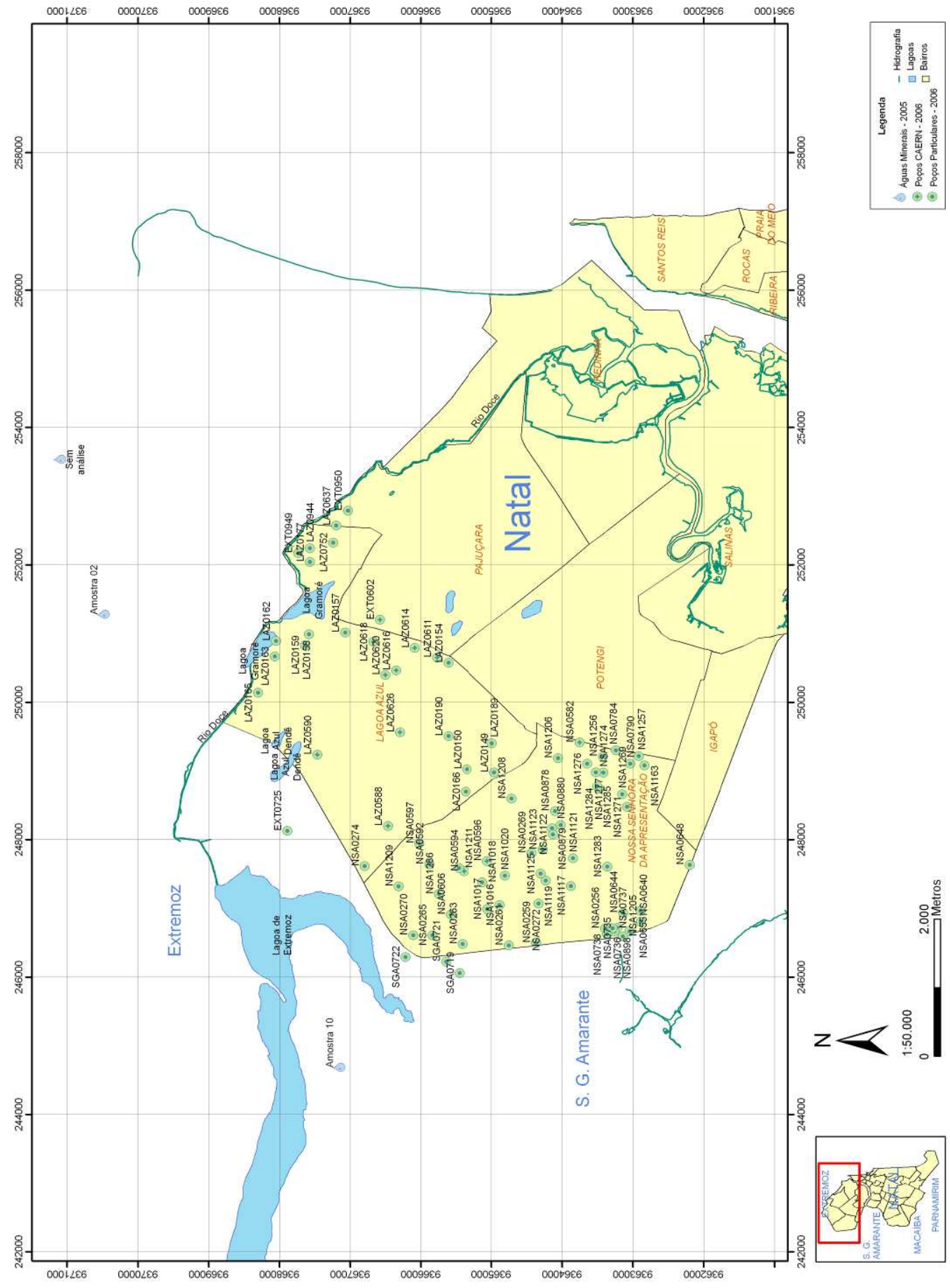

Figura 2: Mapa de localização dos poços estudados na Região Norte da Grande Natal 


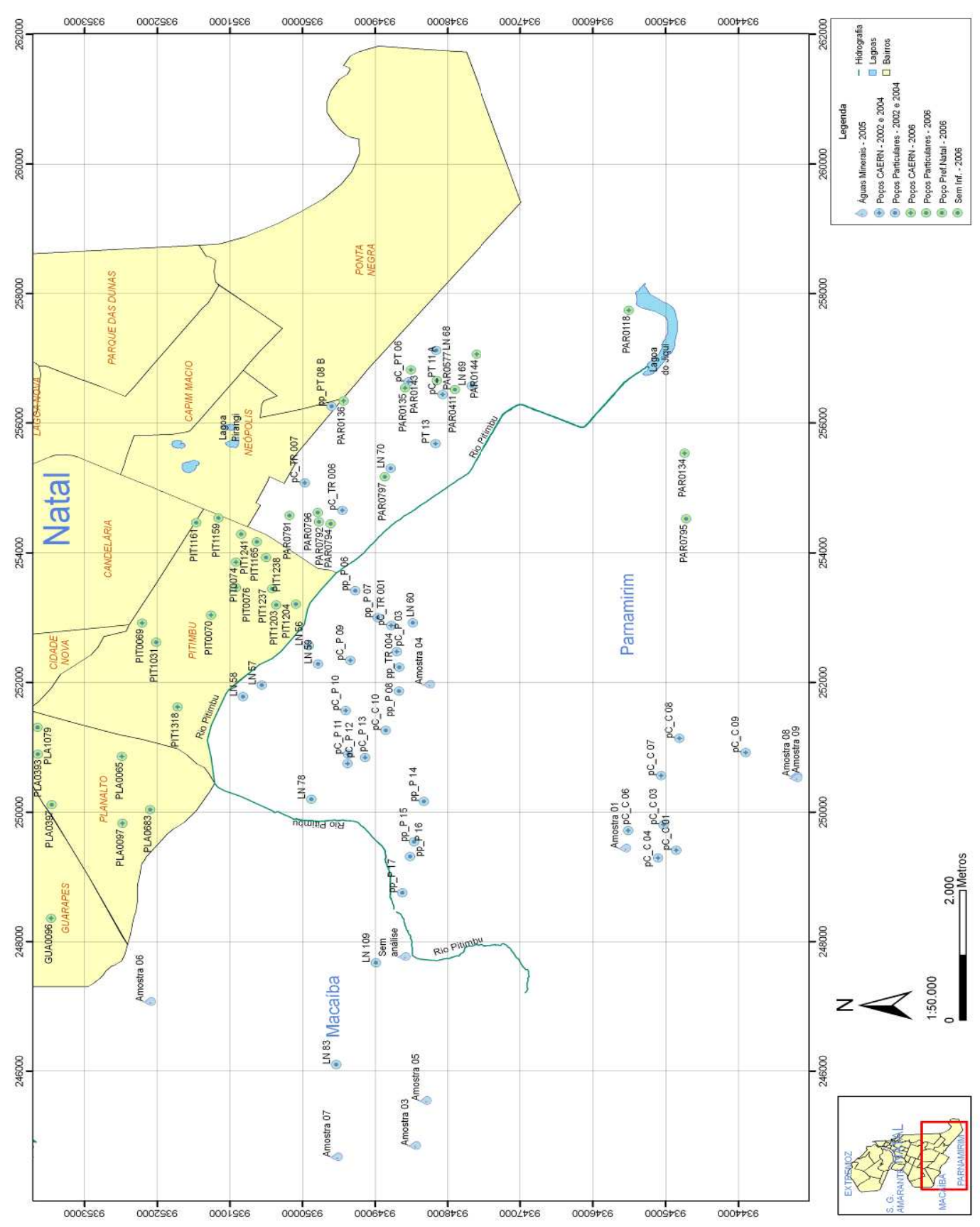

Figura 3: Mapa de localização dos poços estudados na Região Sul da Grande Natal 


\section{RESULTADOS E DISCUSSÕES}

Existem 15 fontes de água mineral no Rio Grande do Norte, sendo que 12 dessas estão localizadas na região da Grande Natal. No entanto, na pesquisa desenvolvida durante o ano de 2005, foram realizadas análises em dez das 12 marcas existentes.

\section{- Níveis de Nitrato nas Águas Minerais}

A Resolução RDC nº 274 da ANVISA (BRASIL, 2005) traz, dentre outras coisas, os limites máximos que devem ser obedecidos nas águas minerais para substâncias químicas que representam risco à saúde. Nesse sentido, o VMP para concentrações de nitrato em águas minerais é $50 \mathrm{mgNO}_{3}{ }^{-} / \mathrm{L}$.

Na Tabela 1, observam-se as concentrações de nitrato que essas águas apresentaram no ano em que suas respectivas indústrias foram autorizadas a operar. Na Tabela 2, são apresentadas as três amostragens realizadas durante o projeto de pesquisa de 2005, além do seu valor médio de nitrato calculado como nitrato.

Tabela 1: Concentrações iniciais do íon nitrato nas águas minerais

\begin{tabular}{|lcc|}
\hline \multicolumn{1}{c}{ Águas Minerais } & Ano de abertura & Nitrato $\left(\mathbf{m g N O}_{\mathbf{3}}{ }^{-} \mathbf{L} \mathbf{L}\right)$ \\
Amostra 01 & 1985 & 12,50 \\
Amostra 02 & 2001 & 4,20 \\
Amostra 03 & 1999 & 4,70 \\
Amostra 04 & 1987 & 0,95 \\
Amostra 05 & 1993 & 0,00 \\
Amostra 06 & 1999 & 0,37 \\
Amostra 07 & 1999 & 4,53 \\
Amostra 08 & - & - \\
Amostra 09 & 1993 & 11,93 \\
Amostra 10 & 2002 & 1,20 \\
Amostra 11 & 1993 & 3,35 \\
Amostra 12 & - & - \\
\hline
\end{tabular}

Fonte: adaptado, Departamento Nacional de Produção Mineral - DNPM (2006).

Tabela 2: Concentrações do íon nitrato nas águas minerais durante o projeto de pesquisa de 2005

\begin{tabular}{|lccccc|}
\hline Aguas Minerais & $\mathbf{1}^{\mathbf{a}}$ análise & $\mathbf{2}^{\mathbf{a}}$ análise & $\mathbf{3}^{\mathbf{a}}$ análise & Ano & Concentrações médias (mgNO $\left.\mathbf{3}^{\mathbf{T}} / \mathbf{L}\right)$ \\
Amostra 01 & 18,65 & 20,21 & 18,50 & 2005 & 19,12 \\
Amostra 02 & 3,52 & 3,75 & 3,70 & 2005 & 3,66 \\
Amostra 03 & 6,05 & 3,03 & - & 2005 & 4,54 \\
Amostra 04 & 4,90 & 5,64 & 5,23 & 2005 & 5,26 \\
Amostra 05 & 0,10 & 1,41 & 1,05 & 2005 & 0,85 \\
Amostra 06 & 0,31 & 0,36 & 0,44 & 2005 & 0,37 \\
Amostra 07 & 3,55 & 3,40 & 2,60 & 2005 & 3,18 \\
Amostra 08 & 45,00 & 52,20 & 47,00 & 2005 & 48,07 \\
Amostra 09 & 59,20 & 49,15 & 63,55 & 2005 & 57,30 \\
Amostra 10 & 3,68 & 3,17 & 2,10 & 2005 & 2,98 \\
\hline
\end{tabular}

Fonte: Nóbrega e Vale, 2005.

Após a obtenção desses dados, tornou-se possível a elaboração da Figura 4, a qual permite a visualização do comportamento das concentrações de nitrato nos poços de água mineral. 


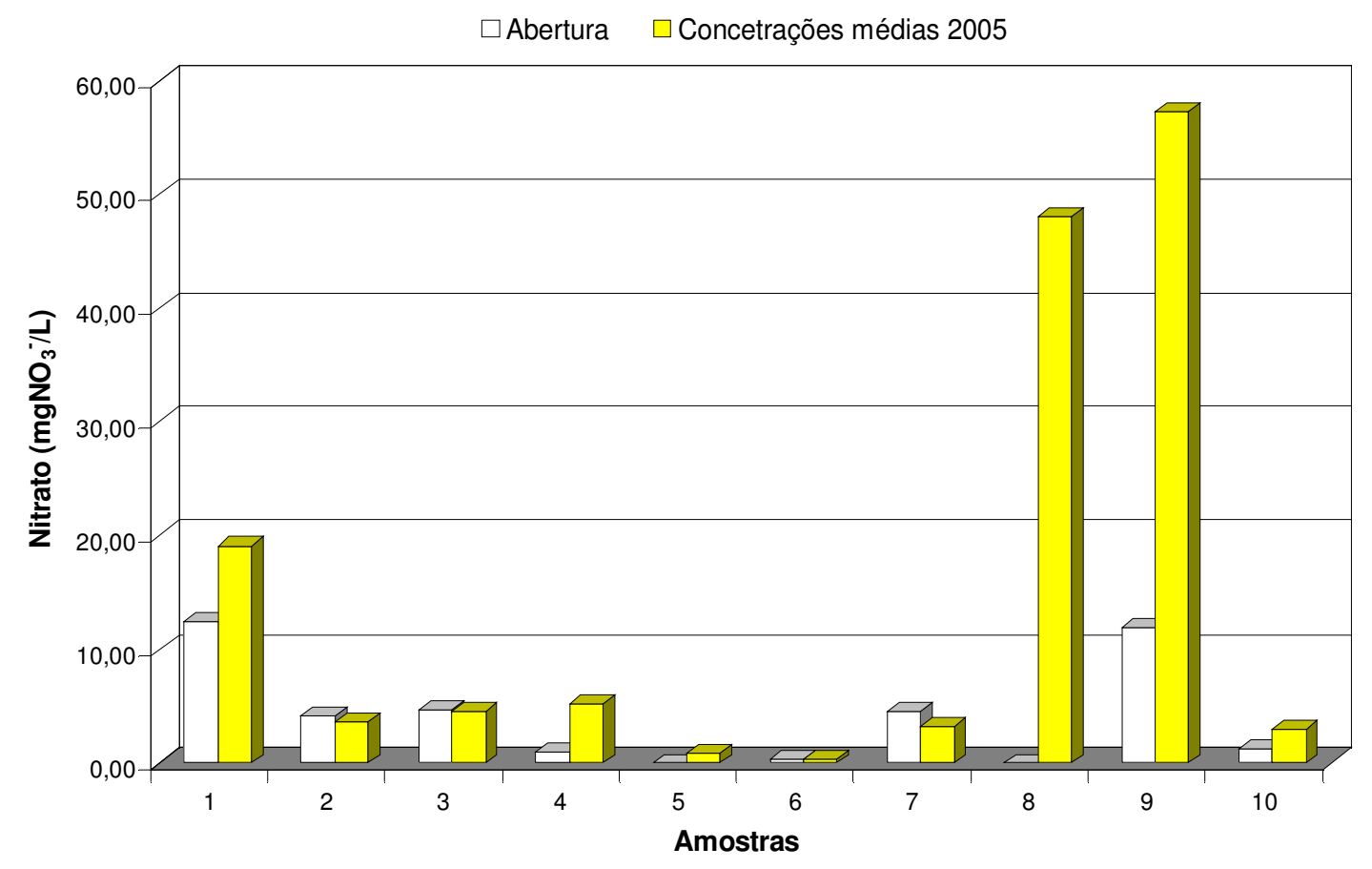

Figura 4: Comparação dos níveis de nitrato nas águas minerais

A partir das informações contidas na Figura 4, observa-se com destaque as amostras 1, 8 e 9. Em relação à Amostra 1, constata-se que houve um incremento de 52,96\% no nível de $\mathrm{NO}_{3}{ }^{-}$ao longo de 20 anos. Já a amostra 9 teve seu nível de nitrato aumentado em $480 \%$ em relação à concentração que se tinha no ano de 1993, e a 8, apesar de não conter informações sobre o ano de abertura da fonte, apresentou em 2005 concentração bastante elevada. As amostras 4 e 10 apresentaram um certo aumento na concentração do íon nitrato, 315 e $148 \%$ respectivamente, no entanto, em termos de $\mathrm{mg} / \mathrm{L}$ os valores encontrados continuam bem abaixo dos valores máximos permitidos presentes na legislação. As amostras 2, 3, 5, 6 e 7 não apresentaram em 2005 alterações significativas quando comparadas com as concentrações do ano de abertura de cada poço, permanecendo assim com os valores bem abaixo dos $50 \mathrm{mg} / \mathrm{L}$ permitidos pela legislação.

\section{- Níveis de Nitrato nas Áreas Próximas às Fontes de Águas Minerais}

A Portaria no 518 de 2004 do Ministério da Saúde (BRASIL, 2004) estabelece os procedimentos e responsabilidades ao controle e vigilância da qualidade da água para consumo humano e seus padrões de potabilidade. Dessa forma, para estar em conformidade com o padrão de substâncias químicas que representam risco à saúde, as águas ditas potáveis devem apresentar como limite de concentração $10 \mathrm{mg} / \mathrm{L}$ de nitrato calculado como nitrogênio.

As águas minerais têm o seu valor máximo de $\mathrm{NO}_{3}{ }^{-}$fixado em $50 \mathrm{mg} / \mathrm{L}$, sendo que esse último teor quando calculado como nitrogênio passa a ser uma concentração de $11,3 \mathrm{mg} / \mathrm{L}$ ou o VMP da Portaria 518, quando calculado como nitrato passa a ser 44,3 mg/L. Com isso constata-se que há uma incompatibilidade entre essas duas legislações. Haja vista que uma água mineral com concentração de nitrato $49 \mathrm{mgNO}_{3}{ }^{-} / \mathrm{L}$ está de acordo com o VMP na sua 
respectiva legislação, no entanto, se transformada para unidade da Portaria 518, tal água passa a ter $11 \mathrm{mgN} / \mathrm{L}$, estando fora dos padrões recomendados para água potável.

$\mathrm{Na}$ maioria das vezes $10 \mathrm{mg} / \mathrm{L}$ de nitrato calculado como $\mathrm{N}$ é o valor adotado como o limite de uma concentração aceitável de contaminação pelo íon nitrato. Entretanto, tendo em vista uma padronização dos dados e que o foco deste trabalho diz respeito às águas minerais, optou-se por adotar $50 \mathrm{mgNO}_{3}{ }^{-} / \mathrm{L}$ como teor máximo permitido.

A partir da constatação de que as áreas nas quais estão localizadas as indústrias de água mineral concentram-se nos municípios de Parnamirim e Macaíba, ao sul de Natal, e na cidade de Extremoz, na parte norte, também foram selecionadas localidades de Natal para entrarem na pesquisa; dessa forma, foram selecionados os bairros de Guarapes, Planalto, Pitimbú, (zona sul) e Lagoa Azul e Nossa Senhora da Apresentação (zona norte).

Dessa forma, os valores de nitrato nessas localidades estão esquematicamente representados na Figura 5.

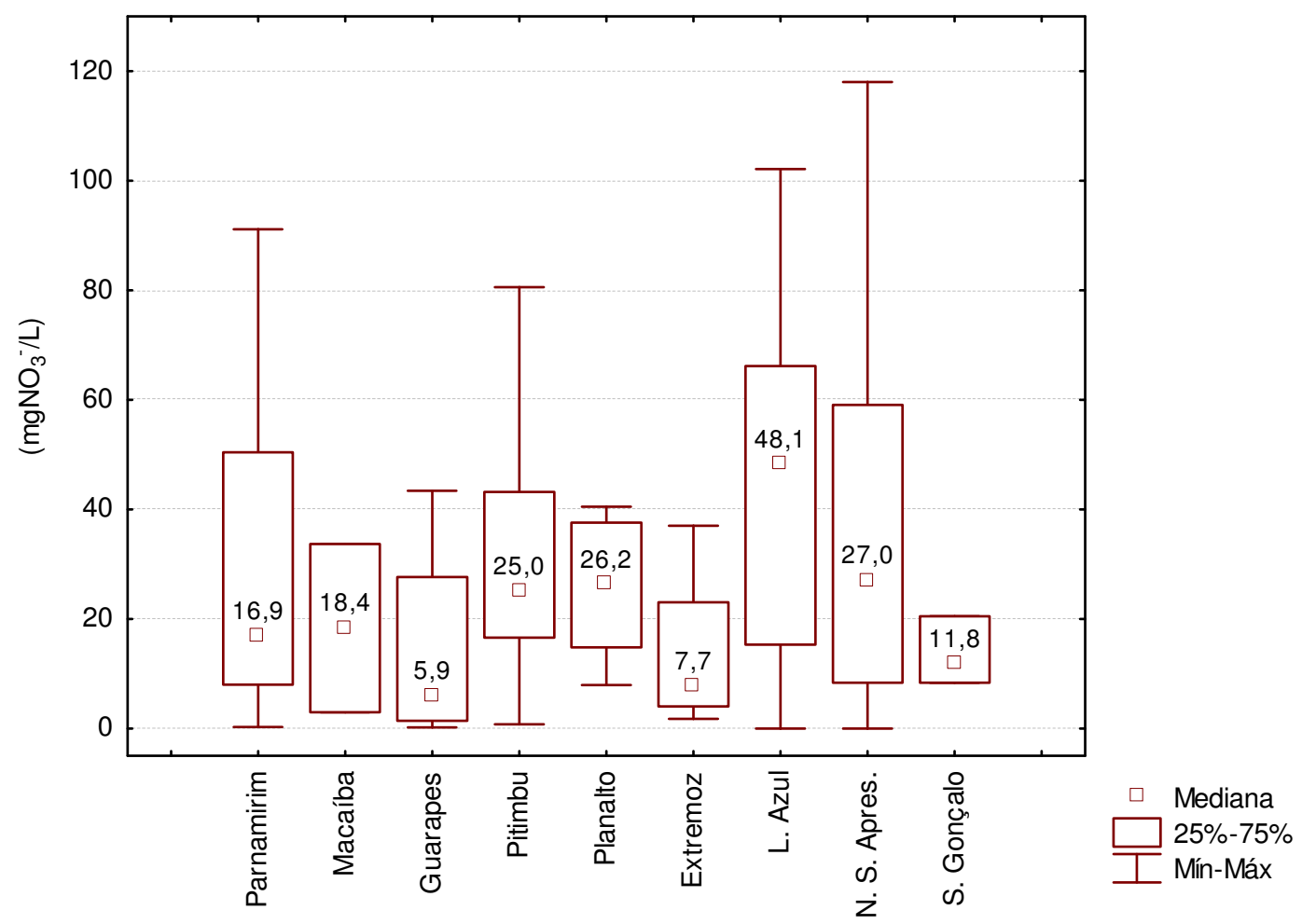

Figura 5: Desenho esquemático com as medianas, quartis e extremos por localidade dos pontos amostrados

Os valores das medianas informados, inicialmente permitem inferir que no bairro Guarapes $50 \%$ dos dados estão abaixo de $6 \mathrm{mg} / \mathrm{L}$. Em Parnamirim, pelo menos a metade dos poços apresentaram valores inferiores a $17 \mathrm{mg} / \mathrm{L}$. Já nos bairros Pitimbú, Planalto e Nossa Senhora da Apresentação o mesmo número de dados esteve abaixo de $28 \mathrm{mg} / \mathrm{L}$. Destaca-se o bairro Lagoa Azul, onde em torno de $50 \%$ dos poços apresentaram valores acima de 50 mg/L. Em relação aos municípios de Macaíba, São Gonçalo e Extremoz, o número de dados foi limitado não podendo ser inferido muito sobre essas regiões. 
De forma mais detalhada, as Tabelas 3, 4, 5, 6 e 7 e as Figuras 6, 7 e 8 apresentam as concentrações de nitrato encontradas nos poços analisados.

Tabela 1: Níveis de nitrato em poços subterrâneos nos municípios de Parnamirim e Macaíba, calculados como Nitrato

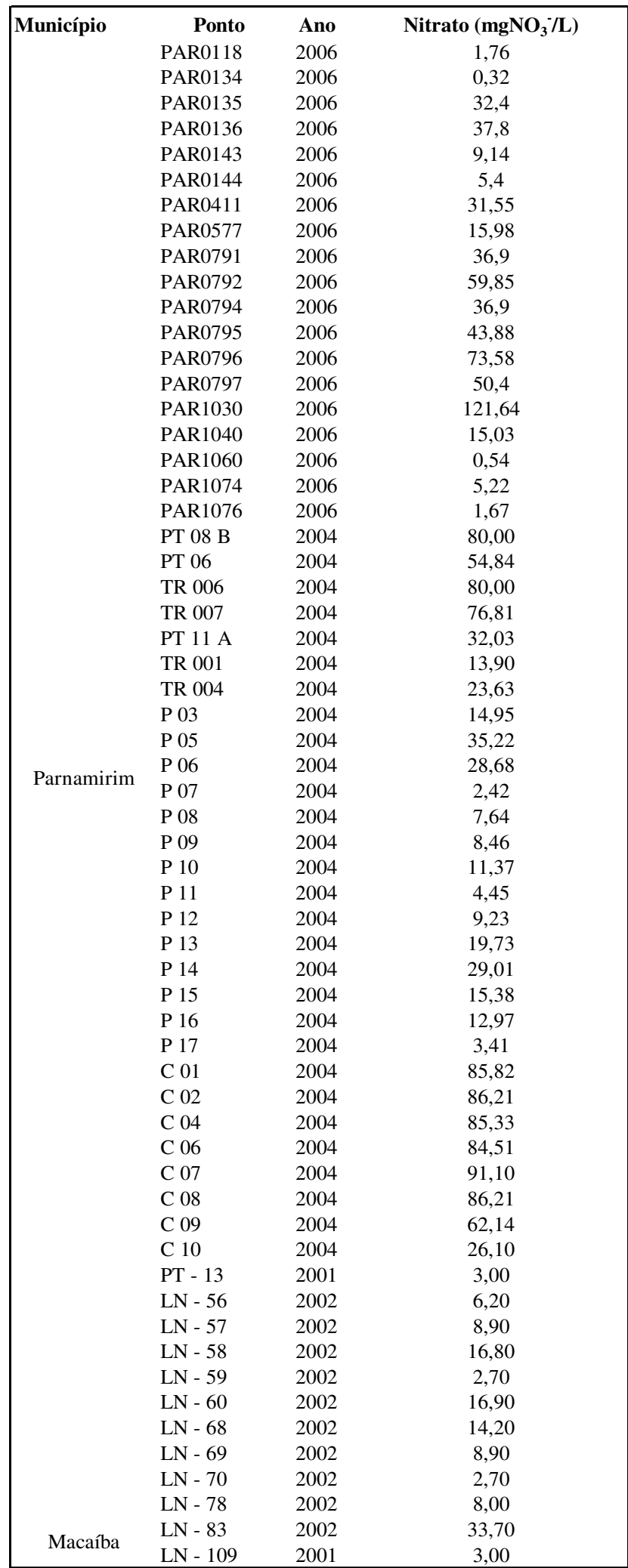

Fonte: Santos (2005), Vasconcelos (2002) e Santos (2006). 


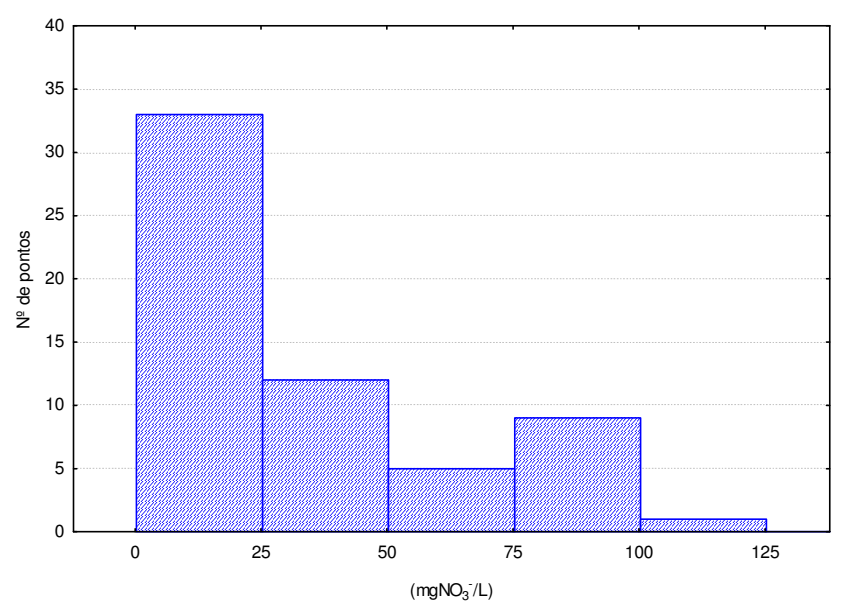

Figura 6: Histograma das concentrações de nitrato nos municípios de Parnamirim e Macaíba

Através do histograma da Figura 6, pode-se observar que a maioria dos pontos analisados em Parnamirim e Macaíba, 75\% dos dados, apresentaram concentrações de nitrato dentro dos limites máximos permitidos. Por outro lado, é em torno de 15 o número de poços com concentrações acima de $50 \mathrm{mg} / \mathrm{L}$, dos quais, por volta de 10 demonstraram estar com níveis do íon acima de $75 \mathrm{mg} / \mathrm{l}$, destacando-se aí pelo menos um poço com concentração de $121 \mathrm{mg} / \mathrm{L}$.

Tabela 2: Níveis de nitrato em poços subterrâneos nos municípios de Extremoz e São Gonçalo do Amarante, calculados como Nitrato

\begin{tabular}{|crcc|}
\hline Município & Ponto & Ano & Nitrato $\left(\mathbf{m g N O}_{3}{ }^{-} / \mathbf{L}\right)$ \\
& EXT0602 & 2006 & 37,04 \\
Extremoz & EXT0725 & 2006 & 6,30 \\
& EXT0949 & 2006 & 9,09 \\
& EXT0950 & 2006 & 1,76 \\
São Gonçalo do & SGA0719 & 2006 & 20,48 \\
Amarante & SGA0721 & 2006 & 11,79 \\
& SGA0722 & 2006 & 8,33 \\
\hline
\end{tabular}

Fonte: Santos (2006).

Pelo fato do número de dados disponíveis em relação aos Municípios de Extremoz e São Gonçalo do Amarante ter sido limitado, o estudo estatístico através do histograma não foi possível. De maneira geral, entretanto, do total de sete amostras analisadas, há pelo menos quatro dessas com valores abaixo de $10 \mathrm{mg} / \mathrm{L}$. Observa-se ainda que as três amostras restantes apresentam-se bastante distintas, com concentrações que variaram um pouco acima de $10 \mathrm{mg} / \mathrm{L}$ e menor que $40 \mathrm{mg} / \mathrm{L}$.

Do histograma representado na Figura 7, obtido a partir da Tabela 5, observa-se que a maioria absoluta dos pontos amostrados (cerca de 47, de um total de 52) apresentaram concentrações dentro do permitido pela legislação, sendo que os casos em desacordo com o valor máximo permitido encontram-se dispersos em apenas 5 (10\% dos dados) pontos. Entretanto, pelo menos três amostras apresentaram níveis de nitrato bastante altos, destacando-se aí pelo menos duas dessas localizadas no bairro Guarapes com concentrações de 176 e $233 \mathrm{mg} / \mathrm{L}$, esse último sendo mais do que o triplo permitido pela legislação. 
Tabela 3: Níveis de nitrato em poços subterrâneos em alguns bairros da Zona Oeste de Natal

\begin{tabular}{|c|c|c|c|}
\hline \multirow[t]{16}{*}{ Bairro } & Ponto & Ano & Nitrato $\left(\mathrm{mgNO}_{3}{ }^{-} / \mathrm{L}\right)$ \\
\hline & GUA0096 & 2006 & 0,18 \\
\hline & GUA0399 & 2006 & 14,27 \\
\hline & GUA0402 & 2006 & 14,54 \\
\hline & GUA0768 & 2006 & 20,93 \\
\hline & GUA0770 & 2006 & 0,95 \\
\hline & GUA0903 & 2006 & 6,75 \\
\hline & GUA0904 & 2006 & 1,4 \\
\hline & GUA0907 & 2006 & 27,68 \\
\hline & GUA0908 & 2006 & 233,55 \\
\hline & GUA0926 & 2006 & 0,68 \\
\hline & GUA0927 & 2006 & 0,68 \\
\hline & GUA0929 & 2006 & 1,94 \\
\hline & GUA0930 & 2006 & 3,2 \\
\hline & GUA0931 & 2006 & 9,36 \\
\hline & GUA0932 & 2006 & 0,36 \\
\hline \multirow[t]{22}{*}{ Guarapes } & GUA0933 & 2006 & 5,94 \\
\hline & GUA0934 & 2006 & 2,61 \\
\hline & GUA0935 & 2006 & 7,29 \\
\hline & GUA1029 & 2006 & 27,99 \\
\hline & GUA1032 & 2006 & 15,3 \\
\hline & GUA1033 & 2006 & 175,64 \\
\hline & GUA1034 & 2006 & 43,43 \\
\hline & GUA1035 & 2006 & 4,68 \\
\hline & GUA1038 & 2006 & 5,94 \\
\hline & GUA1039 & 2006 & 1,67 \\
\hline & GUA1072 & 2006 & 1,4 \\
\hline & GUA1073 & 2006 & 27,81 \\
\hline & GUA1075 & 2006 & 5,81 \\
\hline & GUA1088 & 2006 & 34,16 \\
\hline & GUA1151 & 2006 & 0,72 \\
\hline & GUA1152 & 2006 & 29,75 \\
\hline & PIT0069 & 2006 & 80,6 \\
\hline & PIT0070 & 2006 & 55,67 \\
\hline & PIT0074 & 2006 & 43,2 \\
\hline & PIT0076 & 2006 & 36,9 \\
\hline & PIT1031 & 2006 & 0,77 \\
\hline & PIT1159 & 2006 & 22,32 \\
\hline \multirow{11}{*}{ Pitimbú } & PIT1161 & 2006 & 6,75 \\
\hline & PIT1165 & 2006 & 37,8 \\
\hline & PIT1203 & 2006 & 26,96 \\
\hline & PIT1204 & 2006 & 23 \\
\hline & PIT1237 & 2006 & 65,66 \\
\hline & PIT1238 & 2006 & 8,96 \\
\hline & PIT1241 & 2006 & 16,61 \\
\hline & PIT1318 & 2006 & 17,55 \\
\hline & PLA0065 & 2006 & 26,24 \\
\hline & PLA0097 & 2006 & 7,92 \\
\hline & PLA0393 & 2006 & 14,85 \\
\hline \multirow[t]{4}{*}{ Planalto } & PLA0397 & 2006 & 14,85 \\
\hline & PLA0683 & 2006 & 31,32 \\
\hline & PLA0769 & 2006 & 37,58 \\
\hline & PLA1079 & 2006 & 40,5 \\
\hline
\end{tabular}

Fonte: Santos (2006). 


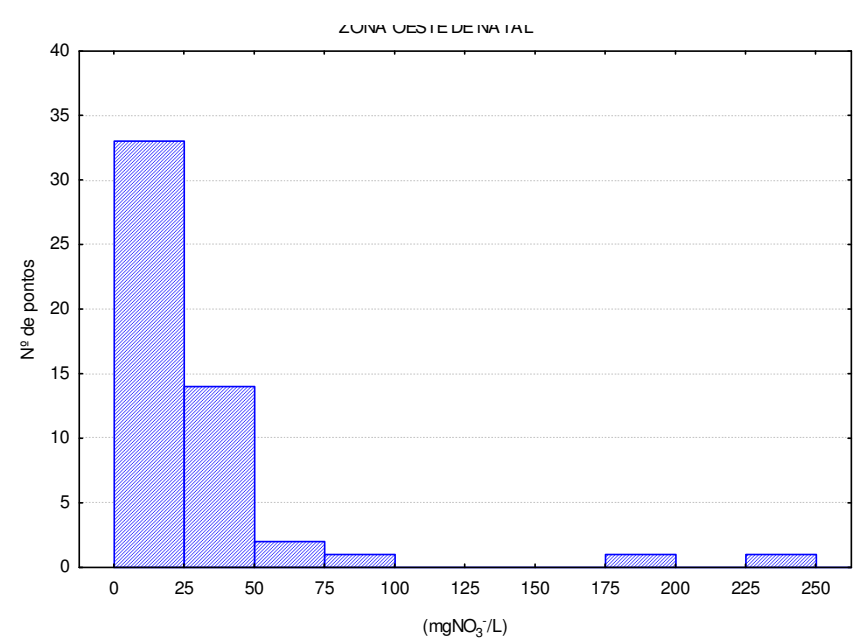

Figura 7: Histograma das concentrações de nitrato nos bairros Guarapes, Pitimbú e Planalto, zona oeste de Natal

Tabela 4: Níveis de nitrato em poços subterrâneos no bairro Lagoa Azul, Zona Norte de Natal

\begin{tabular}{|lcc|}
\hline Ponto & Ano & Nitrato $\left(\mathbf{m g N O}_{\mathbf{3}}{ }^{-\mathbf{L}} \mathbf{\text { ) }}\right.$ \\
LAZ0149 & 2006 & 84,6 \\
LAZ0150 & 2006 & 66,15 \\
LAZ0154 & 2006 & 18,72 \\
LAZ0157 & 2006 & 102,15 \\
LAZ0158 & 2006 & 48,15 \\
LAZ0159 & 2006 & 4,05 \\
LAZ0162 & 2006 & 48,15 \\
LAZ0163 & 2006 & 7,65 \\
LAZ0165 & 2006 & 15,3 \\
LAZ0166 & 2006 & 51,3 \\
LAZ0177 & 2006 & 1,98 \\
LAZ0189 & 2006 & 57,6 \\
LAZ0190 & 2006 & 0,9 \\
LAZ0588 & 2006 & 72,23 \\
LAZ0590 & 2006 & 46,13 \\
LAZ0609 & 2006 & 0 \\
LAZ0611 & 2006 & 60,21 \\
LAZ0614 & 2006 & 31,86 \\
LAZ0616 & 2006 & 69,93 \\
LAZ0618 & 2006 & 98,19 \\
LAZ0620 & 2006 & 64,89 \\
LAZ0626 & 2006 & 32,36 \\
LAZ0637 & 2006 & 48,15 \\
LAZ0752 & 2006 & 76,73 \\
LAZ0944 & 2006 & 5,94 \\
\hline
\end{tabular}

Fonte: Santos (2006). 
Tabela 5: Níveis de nitrato em poços subterrâneos no bairro Nossa Senhora da Apresentação, Zona Norte de Natal

\begin{tabular}{|c|c|c|}
\hline Ponto & Ano & Nitrato $\left(\mathrm{mgNO}_{3}{ }^{-} / \mathrm{L}\right)$ \\
\hline NSA0256 & 2006 & 6,75 \\
\hline NSA0259 & 2006 & 20,7 \\
\hline NSA0261 & 2006 & 3,15 \\
\hline NSA0263 & 2006 & 14,27 \\
\hline NSA0265 & 2006 & 14,4 \\
\hline NSA0269 & 2006 & 5,85 \\
\hline NSA0270 & 2006 & 5,4 \\
\hline NSA0272 & 2006 & 7,65 \\
\hline NSA0274 & 2006 & 6,3 \\
\hline NSA0582 & 2006 & 115,02 \\
\hline NSA0592 & 2006 & 8,28 \\
\hline NSA0594 & 2006 & 28,71 \\
\hline NSA0596 & 2006 & 46,58 \\
\hline NSA0597 & 2006 & 7,52 \\
\hline NSA0606 & 2006 & 8,28 \\
\hline NSA0640 & 2006 & 92,79 \\
\hline NSA0644 & 2006 & 56,3 \\
\hline NSA0648 & 2006 & 85,95 \\
\hline NSA0655 & 2006 & 57,92 \\
\hline NSA0735 & 2006 & 29,16 \\
\hline NSA0736 & 2006 & 8,33 \\
\hline NSA0737 & 2006 & 28,8 \\
\hline NSA0738 & 2006 & 8,33 \\
\hline NSA0784 & 2006 & 157,14 \\
\hline NSA0790 & 2006 & 19,89 \\
\hline NSA0878 & 2006 & 43,92 \\
\hline NSA0879 & 2006 & 8,33 \\
\hline NSA0880 & 2006 & 58,05 \\
\hline NSA0898 & 2006 & 58,46 \\
\hline NSA1016 & 2006 & 23,4 \\
\hline NSA1017 & 2006 & 11,93 \\
\hline NSA1018 & 2006 & 23,27 \\
\hline NSA1020 & 2006 & 118,04 \\
\hline NSA1117 & 2006 & 16,47 \\
\hline NSA1119 & 2006 & 16,47 \\
\hline NSA1121 & 2006 & 60,8 \\
\hline NSA1122 & 2006 & 210,6 \\
\hline NSA1123 & 2006 & 59,72 \\
\hline NSA1125 & 2006 & 19,67 \\
\hline NSA1163 & 2006 & 50,54 \\
\hline NSA1205 & 2006 & 5,27 \\
\hline NSA1206 & 2006 & 61,29 \\
\hline NSA1208 & 2006 & 28,85 \\
\hline NSA1209 & 2006 & 3,65 \\
\hline NSA1211 & 2006 & 6,53 \\
\hline NSA1256 & 2006 & 53,1 \\
\hline NSA1257 & 2006 & 0 \\
\hline NSA1269 & 2006 & 88,83 \\
\hline NSA1271 & 2006 & 97,83 \\
\hline NSA1274 & 2006 & 61,02 \\
\hline NSA1276 & 2006 & 73,71 \\
\hline NSA1277 & 2006 & 32,81 \\
\hline NSA1283 & 2006 & 25,38 \\
\hline NSA1284 & 2006 & 43,16 \\
\hline NSA1285 & 2006 & 178,02 \\
\hline NSA1286 & 2006 & 16,79 \\
\hline
\end{tabular}

Fonte: Santos (2006). 


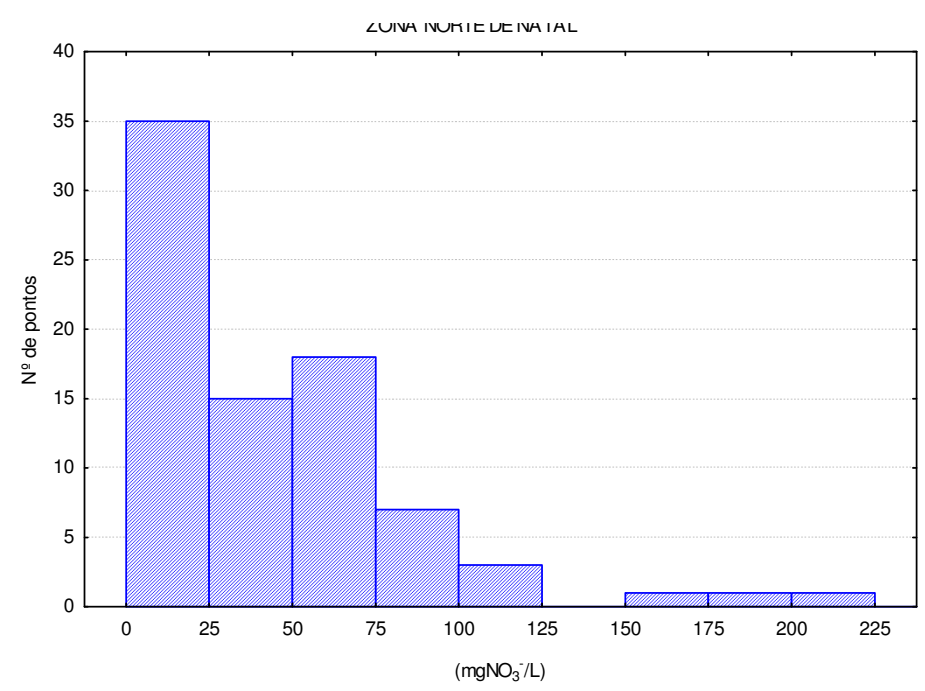

Figura 8: Histograma das concentrações de nitrato nos bairros Lagoa Azul e Nossa Senhora da Apresentação, zona norte de Natal

O que se pode observar a partir das Tabelas 6 e 7 e do histograma que representa os pontos amostrados nos bairros da Zona Norte de Natal (Figura 8), é que existem basicamente dois grupos de concentrações. Por volta de $62 \%$ dos dados obtidos (50 poços) apresentaram níveis abaixo de $50 \mathrm{mg} / \mathrm{L}$, conseqüentemente os $38 \%$ restante possuem concentrações acima de $50 \mathrm{mg} / \mathrm{L}$, destacando-se três pontos, com valores superiores a $150 \mathrm{mg} / \mathrm{L}$, ou seja, o triplo permitido pela legislação.

\section{- Localização Geográfica e Níveis de Nitrato}

Buscando comparar a localização geográfica dos poços de água mineral e seus respectivos níveis de nitrato com os poços de água subterrânea e também com suas concentrações de $\mathrm{NO}_{3}{ }^{-}$, todos os pontos de água foram georreferenciados, obtendo-se as Figuras 9 e 10. 


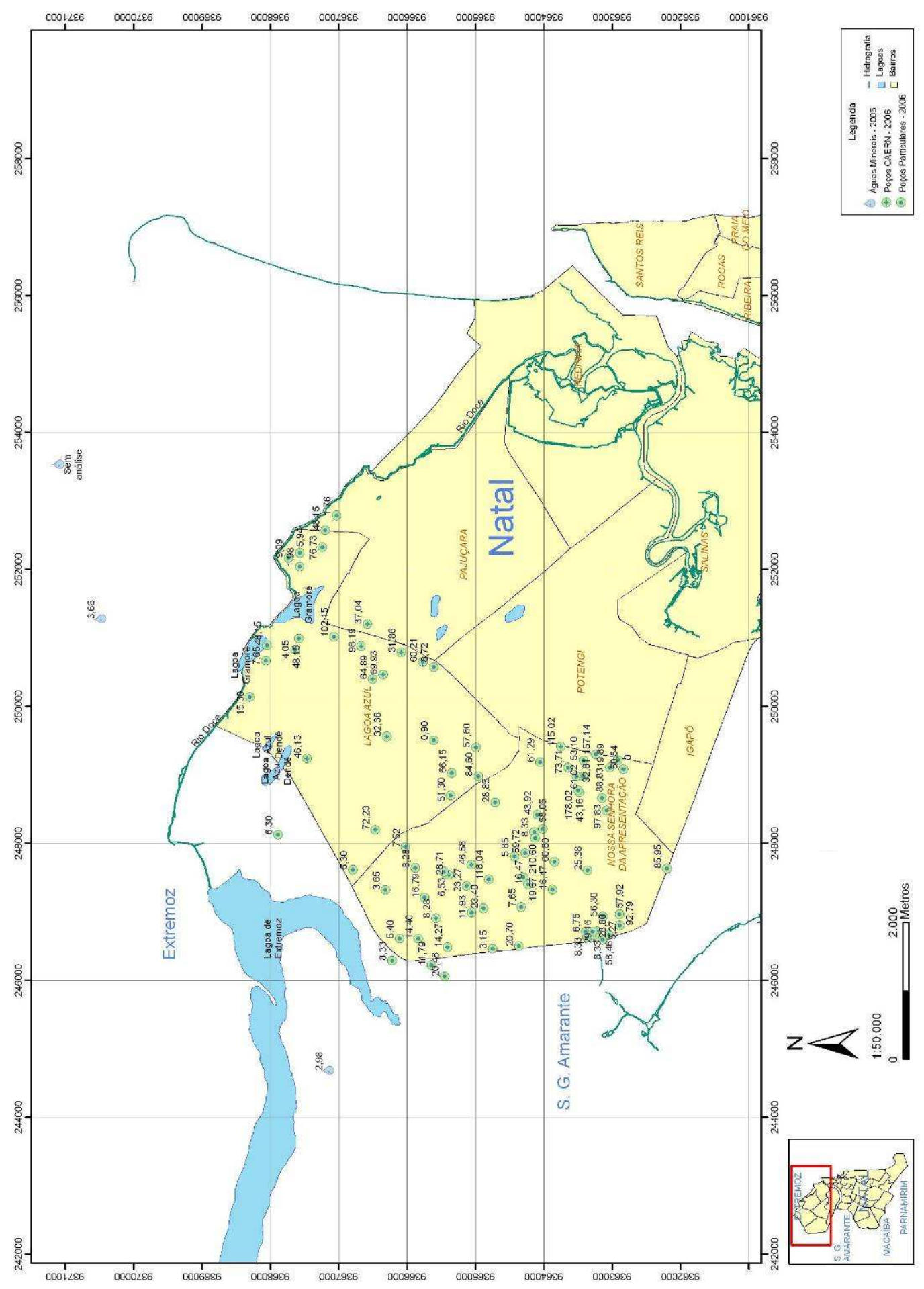

Figura 9: Mapa das concentrações de nitrato nos poços estudados na Região Norte da Grande Natal 


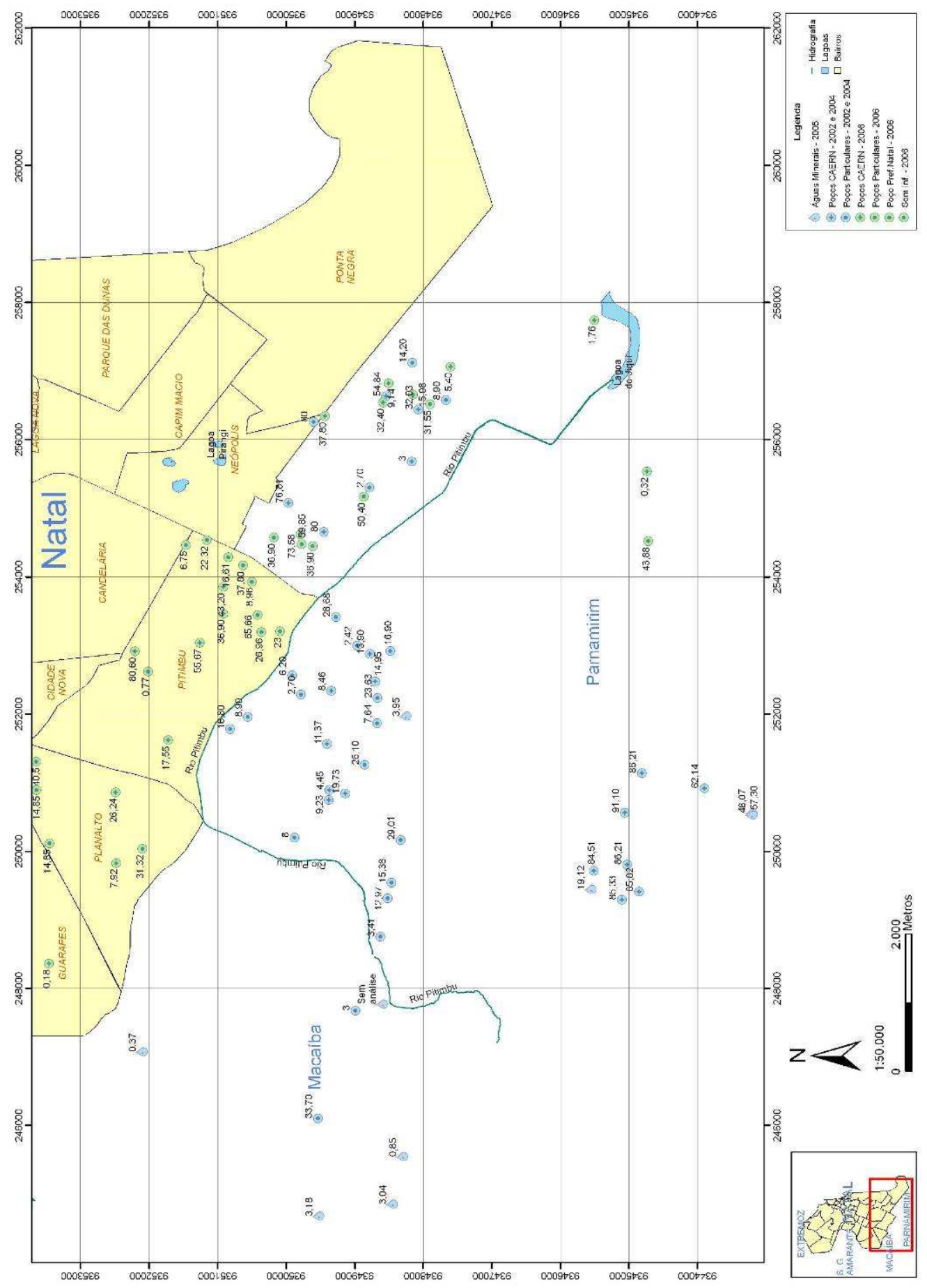

Figura 10: Mapa das concentrações de nitrato nos poços estudados na Região Sul da Grande Natal

Ao analisar os mapas gerados, constata-se que em relação aos poços de água subterrânea localizados na parte norte da região da Grande Natal, as maiores concentrações de nitrato estão presentes, principalmente, na parte sul e leste do bairro Lagoa Azul e sul do bairro 
Nossa Senhora da Apresentação. Geograficamente, esses pontos estão distantes, cerca de três a quatro quilômetros, das indústrias de águas minerais localizadas no município de Extremoz. Ainda se pode constatar que um dos poços minerais se encontra entre as margens da Lagoa de Extremoz, e o outro à margem esquerda do Rio Doce, fato esse que poderia impedir um possível fluxo subterrâneo contaminado por nitrato de dirigir-se até às águas minerais. Tal contexto poderia explicar os baixos valores de nitrato encontrados nas amostras de tais águas.

Para efeito didático, as indústrias de água mineral presentes na parte sul da Região Metropolitana de Natal foram divididas em quatro grupos; os dois primeiros dizem respeito às que estão localizadas na cidade de Macaíba, sendo que um está próximo dos bairros Guarapes e Planalto e o outro se refere às águas que estão concentradas na parte oeste desse município. Já os dois grupos restantes estão fixados no município de Parnamirim, sendo o primeiro localizado ao norte e o outro na região central da sede municipal.

Em relação aos maiores valores de concentrações do $\mathrm{NO}_{3}{ }^{-}$obtidos dos poços dos bairros Guarapes, Planalto e Pitimbú, nota-se que esses estão distantes geograficamente do ponto de água mineral mais próximo dessa região (no mínimo cinco quilômetros), conseqüentemente, as fontes de contaminação que atingiram alguns poços desses bairros também estão distantes dessa água. Nesse sentido, seu valor médio de nitrato apresenta-se menor que $0,5 \mathrm{mg} / \mathrm{L}$.

No que diz respeito ao segundo grupo estudado, o número de poços analisados próximos às águas minerais não foi quantitativamente expressivo - apenas dois dados. Não sendo possível uma análise mais precisa com relação à contaminação nessa região. Entretanto, tendo em vista os valores do íon nitrato nessas águas minerais, constata-se que as três fontes demonstraram estar isentas de uma contaminação.

Dentre as águas minerais localizadas no município de Parnamirim, a que se encontra ao norte do município apresentou concentração de duas a seis vezes menores que os valores dos outros poços subterrâneos mais próximos a ela (em torno de $500 \mathrm{~m}$ ), entretanto os valores desses poços não caracterizam uma contaminação nessa região.

Por fim, as águas minerais encontradas no centro de Parnamirim podem ser subdivididas em dois grupos, um mais no centro e o outro mais ao sul do município. Sendo que no primeiro grupo a concentração média da única fonte de água mineral obtida nessa área, $19,2 \mathrm{mg} / \mathrm{L}$, aparentemente não condiz com os valores de nitrato de poços próximos (300 a $600 \mathrm{~m}$ ) a ela, tendo em vista que esses resultados se apresentaram na faixa de $80 \mathrm{mg} / \mathrm{L}$. Entretanto, dados sobre o fluxo subterrâneo e profundidade desses poços poderiam explicar essa baixa concentração.

Em relação ao segundo grupo analisado se pode constatar que as concentrações médias de nitrato dos dois poços de água mineral foram 57,30 e 48,07 mg/L (Ver Tabela 1, Figura $4 \mathrm{e}$ Figura 10).

Os outros poços de água subterrânea mais próximos do segundo grupo analisado apresentam teores de nitrato $\left(\mathrm{NO}_{3}{ }^{-}\right)$acima do limite máximo permitido e estão distantes 700 e 1700 metros das fontes minerais, ou seja mais distantes do que os poços do primeiro grupo estão do poço de água mineral. No entanto, os valores desse segundo grupo 
demonstram que seus respectivos poços estão mais de acordo com a situação de contaminação caracterizada na área central de Parnamirim.

A partir da discussão acima, acredita-se que a direção do fluxo subterrâneo poderia ser a principal causa do fato do valor de nitrato, em pelo menos um dos poços de água mineral, apresentar uma evolução bastante significativa em apenas 12 anos.

\section{CONSIDERAÇÕES FINAIS}

$\mathrm{O}$ crescimento do mercado das águas minerais envasadas experimentou nos últimos anos um crescimento em escala mundial. O estado do Rio Grande do Norte seguiu essa tendência e atualmente conta com 14 indústrias autorizadas a envasar esse produto. Sendo que a grande maioria dessas empresas encontra-se localizada em três dos municípios pertencentes à Região Metropolitana de Grande Natal (Extremoz, Macaíba e Parnamirim).

De maneira geral, a Região da Grande Natal está localizada em um ambiente que possui geologicamente forte influência do grupo Barreiras, sendo sua hidrogeologia constituída basicamente pelo aqüífero Dunas/Barreiras. De acordo com Melo e Queiros (1998), as características geomorfológicas e geológicas dessa área, dentre as quais se destacam a cobertura superficial de areias de dunas, a formação de bacias fechadas e a ocorrência de lagoas, além da conexão hidráulica das dunas com os sedimentos 'Barreiras', acabam por atribuir ao sistema aquiífero Dunas/Barreiras uma elevada vulnerabilidade à contaminação.

Em relação à expansão da Região Metropolitana de Natal, pôde se observar que a sua população já representa mais de $40 \%$ do total do estado, além de que os municípios de Parnamirim, Macaíba e Extremoz apresentaram, juntamente com São Gonçalo, os maiores índices de crescimento. Entretanto, tanta expansão não é acompanhada de uma infraestrutura de saneamento que comporte todo esse crescimento. Sendo assim, sistemas sépticos continuam a ser usados como alternativas de destino final de efluente urbano.

Tendo em vista todo esse contexto geológico, sócio-econômico e ambiental analisado acima, esse estudo contribui para a constatação de que dentre as amostras de águas minerais analisadas, em sua grande maioria, essas demonstraram estar em acordo com o limite máximo permitido pela legislação (RDC 274/05) no que diz respeito aos valores de nitrato.

Entretanto, ficou comprovado pelos dados analisados que, dois poços de água mineral analisados e localizados na cidade de Parnamirim foram atingidos pela contaminação, contaminação essa que está comprometendo a qualidade de diversos poços de abastecimento público daquela comunidade.

Vale salientar que uma análise mais detalhada da atual situação dos poços de água mineral não foi possível, tendo em vista que dados como profundidade dos poços, fluxo subterrâneo e perfil topográfico não estiveram disponíveis para serem analisados.

Por fim, este trabalho acaba por chamar a atenção para uma realidade que já vem sendo discutida a tempo suficiente para atitudes serem tomadas. No entanto, o que se observa é uma piora contínua na situação da qualidade do aqüífero. 
Sendo assim, e diante da importância que representam as águas subterrâneas, várias medidas devem ser implementadas, dentre as quais se sugere: a realização de um projeto que objetive o cadastramento e nivelamento de poços subterrâneos nas outras cidades pertencentes à Região Metropolitana de Natal, tornando-se possível retratar de forma precisa a real situação de toda região, e seu conseqüente monitoramento; fiscalização no processo de perfuração de poços subterrâneos; controle das possíveis fontes poluidoras; e em longo prazo, a implementação de rede de esgotamento sanitário em caráter global.

\section{REFERÊNCIAS BIBLIOGRÁFICAS}

BRASIL. Agência Nacional de Vigilância Sanitária. Resolução RDC n ${ }^{0} 274$ de 22 de setembro de 2005. Diário Oficial da República Federativa do Brasil. Poder Executivo, Brasília, 23 de setembro de 2005.

BRASIL. Ministério da Saúde. Portaria n ${ }^{\circ}$ 518, de 25 de março de 2004. Diário Oficial da República Federativa do Brasil. Poder Executivo, Brasília, 26 de março de 2004.

DNPM. DEPARTAMENTO NACIONAL DA PRODUÇÃO MINERAL. Explorar água mineral. $\quad$ Disponível http://www.dnpm.gov.br/conteudo.asp?IDSecao=64\&IDPagina=59.

Acesso em: 04 de janeiro de 2006.

MELO, José Geraldo e QUEIROS, Marcelo Augusto. Situação atual da explotação das águas subterrâneas na região da Grande Natal - RN, Br. Congresso Latinoamericano de hidrologia subterrânea 4, 1998.

NÓBREGA, Mariana Magna Santos da e VALE, Milton Bezerra do. Avaliação preliminar da qualidade das águas minerais na Grande Natal. Congresso de Iniciação Científica do CEFET-RN 3, 2005.

PREFEITURA MUNICIPAL DO NATAL. Secretaria Municipal de Meio Ambiente e Urbanismo. Anuário Natal 2006. Municípios da Região Metropolitana. Natal (RN), 2006. 300p.:il.

SANTOS, Paula Rafhaela Silva dos. Avaliação das concentrações de nitrato nas águas subterrâneas utilizadas para abastecimento na zona norte urbana de Parnamirim-RN. Monografia (Graduação Tecnologia em Meio Ambiente) - Gerência de Recursos Naturais, Centro Federal de Educação Tecnológica do Rio Grande do Norte, Natal (RN), 2005. 77p.

SANTOS, Jerônimo Pereira dos (Coord.). Cadastramento e Nivelamento de Poços do Aquíffero Barreiras no Município do Natal/RN. CEFETRN/FUNCERN/SERHID/PROÁGUA/IGARN. Relatório Final Volume I. 2006. 198p. Inédito.

VASCONCELOS, Nelson Silveira. O avanço da contaminação por nitrato nas águas subterrâneas da zona sul de Natal/RN. Dissertação (Mestrado em Geociências) Departamento de Geologia, Universidade Federal do Rio Grande do Norte, Natal, 2002. 98p. 